\title{
HOTFIRE TESTING OF A SSME HPOTP WITH AN ANNULAR HYDROSTATIC BEARING
}

\author{
Steven A. Nolan and Robert I. Hibbs \\ Rockwell International \\ Rocketdyne Division \\ Canoga Park, California
}

and

Gary G. Genge

NASA George C. Marshall Space Flight Center Marshall Space Flight Center, Alabama

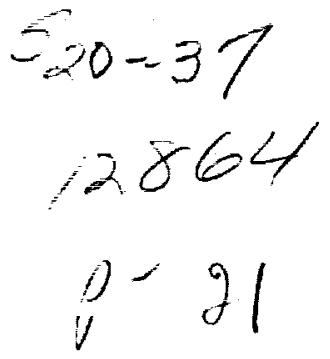

\begin{abstract}
A new fluid film bearing package has heen tested in the Space Shuttle Main Engine (SSME) High Pressure Oxygen Turbopump (HPOTP). This fluid film element functions as both the pump end hearing and the preburner pump rear wear ring seal. Most importantly, it replaces a duplex hall hearing package which has been the primary life limiting component in the turbopump. The design and predicted performance of the turhopump are reviewed. Results are presented for measured pump and hearing performance during testing on the NASA Technology Test Bed (TTB) Engine localted at Marshall Space Flight Center, Alabama. The most significant results were uhtained from proximity prohes loculed in the hearing hore which revealed large subsynchronous precession all len percent of shaft speed during engine start which subsided prior fo mainstage power levels and reappeared during engine shutdown at equivalent power levels below $65 \%$ of nominal. This phenomenon has been attributed to rotating stall in the diffuser. The proximity probes also revealed the location of the hearing in the hore for different operating speeds. Pump vihration characteristics were improved as compared to pumps tested with hall hearings. After seven starts and more than 700 seconds of testing, the pump showed no signs of performance degradation.
\end{abstract}

\section{Introduction}

Annular seals were developed and used as leakage control devices and in that capacity werc Jesigned for optimum pump efficiency. Lomakin' pointed out that annular seals develop significant direct stiffness while in the centered, zero-eccentricity positjon and can inlluence the rotordynamics of a pump). Later, Black ${ }^{2}$, Jensisen ${ }^{3}$, and Black and Jensien ${ }^{+.5}$ investigalled and explained the influence of seal forces on the rotordynamic behavior of pumps.

The term damper seal was conceived to describe an annular seal which has been intentionally roughened. This delinition grew out of the work by von Pragenau" who analytically predicted thalt roughness in an annular seal would increase damping and reduce leakage. This was subsequently supported by the test dala and analysis of Childs and Kim ${ }^{7,8,9}$, Childs and Garcia'", and Kim and Childs". Childs tested many different roughness patterns including hole, post, sawt(o)dh, knurl, helically grooved, and circumferentially grooved. The test results showed that rough seals 
produced more damping than smooth seals and that the hole pattern seal could he optimized for maximum damping.

The first intentional implementation of damping seal technology was in the SSME Phase II HPOTP shown in Figure 1. Wear ring labyrinth seals on the Phase I preburner pump impeller were replaced with damping seals. The knurl pattern and process were developed at Rocketdyne specifically for this purpose and were subsequently tested hy Childs and $\mathrm{Kim}^{7}$. Significant reductions in pump dynamic loads and improvement in rotor stahility resulted.

During SSME testing, hall hearing wear has been a recurring life limiting issue. Primarily, the wear of the pump end hearings has limited the life of the turbopump and has necessitated periodic refurhishment. Recently, there have heen several events during the testing of the SSME HPOTP which resulted in reduced hall hearing stiffness indicating that the turbopump could operate safely on the damping seal alone. A subsequent review of component measurement and test data from previous testing slowed that the turbopump had operated safely on the damping seal alone a minimum of six different times without significant degradation in performance. Based on this evidence, redesign of the turbopump without pump end ball bearings seemed feasible.

The design concept chosen is illustrated in Figure 2 (Scharrer et al. ${ }^{12}$ ). The figure shows that the pump end hearings could be eliminated in favor of a single damping seal located at approximately the same axial plane. Since the damping seal will now be the primary load carrying element, it has been renamed an annular hydrostatic hearing. This paper presents the predicted and experimentally measured performance of the bearing design. In addition, the rotordynamic and hydrodynamic performance of the hydrostatic hearing supported turbopump will be compared with that of the current ball hearing supported pump.

\section{Requirements}

The hearing design required substantial parametric evaluation hefore arriving at the current fully tapered, fully roughened annular hydrostatic bearing design. Parametric studies of geometry and contiguration were considered to optimize the design in order to meet the hydrodynamic and rotordynamic requirements of the pump end hearing for the SSME HPOTP. Details of the design considerations are presented in Scharrrer et al. ${ }^{12}$. The final design is similar to the current Phase II SSME HPOTP prehurner pump damping seal and its well Jocumented performance in llight contiguration SSME pumps.

The design ohjective was to increase the rotordynamic critical speed and stahility margins as shown in Figure 3 as well as address the remaining turhine end hearings. Ioads. It was also of particular interest to ensure the implementation of the pump end hydrostatic hearing did not result in detrimental loads on the remaining rolling element hearings. Based on these requirements the pump end hearing targets were $175 \mathrm{MN} / \mathrm{m}(1.0 \mathrm{E} 6 \mathrm{ht} / \mathrm{in})$ direct stiffness and $61.2 \mathrm{KN}-\mathrm{s} / \mathrm{m}(350)$ inf-s/in) direct damping. The geometry and clearance tolerances were optimized to meet this requirement. The roturdynamic coefficients of the hearing as a function of shaft speed and eccentricity were provided for the rotordynamic analysis. The analyses included coefficients for minimum, nominal, and maximum conditions resulting from potential variahility of tolerances and pump operating conditions. Stability of the hearing was consistently good throughout the speed paramelric as evidenced hy the whirl frequency ratio (WFR) heing constant at 0.30). The WFR is a ratio of the destahilizing forces, cruss-coupled stiflness, over the stabilizing forces, damping lines synchromous specel. 
The impact of the pump end hydrostatic bearing on the turhine end hall hearing loads was evaluated with transient non-linear rotordynamic analyses performed over the entire pump operating speed range. The results of these analyses for the nominal predicted hydrostatic hearing coefficients are shown in Figure 4. It is evident from this data that the dynamic loads are significantly reduced for pump speeds above 27,000 RPM, which is the primary operating range of this pump. These reductions in alternating loads are a result of the increased critical speed margins on the second mode as well as the additional damping derived from the optimized hearing configuration. Alternating load reductions in excess of $30 \%$ are predicted for FPL operation, 30,000 RPM, and nominal hydrostatic hearing coefficients.

An additional important consideration was the start transient and the potential for substantial wear. Several configurations were considered which attempted to provide for hoth hydrodynamic performance during the start transient and hydrostatic performance at Full Power Level (FPL). The configurations considered were straight, tapered, partially tapered, rough, and partially rough. Although the configurations studied, as discussed in Scharrer et al. ${ }^{12}$, did show some slight advantages to having a partially roughened or partially tapered configuration, the benefits were not substantial enough to justify the added complexity and cost.

In addition to the load impact issue, the transient analysis was utilized to predict rotor deflections for all pump operating conditions. The deflection at the hydrostatic bearing was identified as a control point for the design. Specifically, a $0.0254 \mathrm{~mm}$ (.001 in.) margin against rubbing, between the rotor and stator at the hydrostatic hearing location, was the guideline for all bearing design ranges. This guideline ensured adequate rub inargins at all other axial lociations along the rofor. The maximum deflection of the rotor, fixed and alternating deflections combined, was used fo identify this margin as shown in the sample rotor orbit prediction of Figure 5.

\section{TTB Test Facility}

The Technology Tesi Bed (TTB) facility at the Marshall Space Flight center (MSFC) wals designated choice for testing the axially fed hydrostatic bearing. The facility was developed (1) serve as an accessible platform with capability for testing new technology in large liquid rocket engines. The test stand, formally used for the first stage of the Saturn V, was reactivaled in 1988 as a SSME facility. With run tank capacities of 89,000 liters $(23,500$ gallons) of liquid oxygen (LOX) and 284,000 liters (75,000 gallons) of liquid hydrogen, the TTB facility can operate an SSME over 200 seconds per test depending on the desired thrust profile. TTB can operate the SSME from the engine's upper limit of $111 \%$ of rated power level (RPL) to $80 \%$ of RPL while independently controlling the engine LOX and fuel inlet pressures. The facility can vary the LOX and fuel engine inlet net positive suction pressures (NPSP) over the acceptable range for the SSME. The facility actually operates from 137.9 to $1,034.2 \mathrm{KPa}$ (20 to $150 \mathrm{psi}$ ) ullage pressure for LOX and 55.2 to $344.7 \mathrm{Kpa}$ (8 to $50 \mathrm{psi}$ ) ullage pressure for fuel. Because of its technolugy advancement role, the data collection system has 750 digital channels, 50 samples per second, and 216 analog channels to measure pressure, temperature, vibrations, speed, proximity, and more.

\section{Pump/Engine Insirumentation}

The SSME HPOTP is equipped with pump and turhine end radial accelerometers as well as external strain gages which are typically used for high frequency data evaluation. The pump lested at TTB had live accelerometers on both the pump end and turbine flanges as well as four sirain gages on the pump housing hetween the pump and turbine. The housing strain gages which are typically used for hearing generated frequency detection on Phase II HPOTPs were included on 
the hydrostatic configuration as an additional redundant point of comparison. In addition to the standard instrumentation, the hydrostatic bearing HPOTP contained seven internal strain gages. These gages are located near hearing support locations and intended for qualitative comparison to existing Phase II pump data.

Proximity probes were installed in the hearing in order to provide data for the determination of hearing liftoff/touchdown, rotor position in the bore, rotor orbit size the overall health of the hearing. For this particular pump huild, Kaman proximity probes were chosen. Two pressure and temperature measurement taps were included directly upstream of the bearing inlet and downstream of the hearing exit to asses the hearings performance. Additionally, two pressure sensors were located in the cavity downstream of the hearing to anchor overall pump performance.

\section{Test Plan}

Health monitoring of the entire turhopump was a major issue when the turbopump was tested at TTB. Not only was the operational rubbing of the hydrostatic bearing a concern, but since the rotor response was changed the turbine end bearing life was an issue. Therefore all availahle means were taken to ensure that both the hydrostatic pump end hearing and the turbine end duplex hall hearings were not degrading. In addition to all of the standard SSME HPOTP post test inspections (rotor break/run torque, and visual inspection of turbine section, main pump inducer, number three bearing, and the preburner pump inlet) two additional measurements were included. The normal shaft travel measurement used on a test stand was replaced with a more precise measurement for measuring turhine bearing wear called shaft micro-travel descrihed by Genge ${ }^{13}$ and currently used for all flight HPOTPs. To ensure safety, the micro-travel acceptance limit was set at the current flight limit. The second post test measurement added was a radial "microwiggle" test which delermined the amount of wear in the hydrostatic hearing. The wear guideline imposed on this measurement wass sel as the maximum wear found on the test article which had heen exposed to 60 startstop cycles in a test rig simulator reported hy Scharrer et al. ${ }^{14}$

Acceptance criteria also was set on all data obtained during the hot fire testing which directly related to the operation of either the hydrostatic hearing or the turbine end ball bearings. This included a requirement that the proximity probes show that the rotor lifts off the hydrostatic hearing surface prior to 1.51 seconds into the test, and that they show the rotor maintains a .0254 $\mathrm{mm}(.001 \mathrm{in}$.) radial clearance from the wall during operation. Limits were also placed on the minimum pressure drop across the hydrostatic bearing that would analytically show rotor stability, the temperature rise across the bearing that would indicate operational rubbing, and the pressures in the upstream or downstream cavities heing greater than the structural analysis. The fluid exiting the hydrostatic hearing was also required to be a liquid, not two phase or gaseous. In addition, all of the standard SSME data limits were maintained for the testing of this turbopump. The TTB fircility Optical Plume Anomaly Detector (OPAD) (Cooper et al. ${ }^{15}$ ) data was reviewed with a special emphasis on the presence of silver in the plume.

Initially, a four test scries was planned which would characterize the performance of the hydrostatic bearing at all points in a test matrix containing four power levels and three LOX engine inlet NPSP vilues. During the test series, uncertainty with the proximity prohes led to the addition of an additional lest. The profiles and the lest matrix which shows which test will cvaluate that matrix condition are shown in Figures 6 llorough 11.

The primary uhjective of the lirst lest was to demonstrate that the hearing had the capacity fo lif ofl. However, Jue to thrust halane eoncerns with the HPOTP with tests hetween 1.5 seconds and 
10 seconds, the test was planned for 10 seconds (Figure 6). With the complete 10 seconds, the immediate comparison of the predictions for $100 \%$ power level operations to results from the test also became an objective. The subsequent tests planned in the series were intended $t 0$ asses the hearings capability at all power levels and engine inlet pressures available at TTB with hearing evaluation hetween each test.

Test two was intended to exercise all power levels without variations in inlet pressures to isolatc any response due only to power level changes. With the confidence gained from the second test, the third test was meant to obtain as many of the combination of power level/LOX inlet pressure extremes as possible (Figure 8). From Figure 11, it can be seen that seven of the desired stcady state conditions could be achieved. Once again, this test isolated all power level changes from LOX inlet pressure changes to allow the cause of any potential anomaly to be more easily understood. The fourth test profile was driven by four different factors. The main goals were to complete data collection for the test matrix and to start the pump with the lowest viscosity LOX allowed by the SSME Interface Control Document (or closest attainable by TTB). The low viscosity "hot LOX" would test the lift capability of the bearing in the worst possible fluid state that the bearing could undergo. Additionally a constant power level was maintained at the beginning of the test to evaluate proximity probe thermal characteristics. After completion of the fourth test, a fifth test was added to allow for the thermal stabilization of the proximity prohes al all major power levels (Figure 10).

\section{Test Run Summary}

Testing hegan in March, 1992, with test TTB-029. In spite of a premature cut at 5.2 sec due (1) the High Pressure Fuel Turbopump (HPFTP) exceeding its turhine discharge temperalure redline, examination of the test data showed the primary ohjective was achieved. Although the engine did not reach a steady state condition at $100 \%$ power level, rotor liftuff evaluation was pussible. Additionally, this test did show an unexpected shaft orhit at low power levels which was determined 0 be caused by the rotating stall in the preburner pump impeller discussed later.

Because the primary objective had been achieved, it was decided to continue the series as originally planned. However the TTB-030 was also cut off prematurely only .32 seconds into the test. An engine oxidizer actuator position measurement showed that the valve was opening slower than is allowed during a normal start. Although the engine controller took action to correct the slow opening and was recovering, and the engine shut down as programmed.

With no objectives achieved in TTB-030, the next test profile was a repeat. The test went the full 85 second duration following the profile in Figure 7. All of the steady state data for the nominal engine inlet pressure were collected, and rotor stability was maintained throughout the $8(0 \%(1)$ I(1)\% power level range. The next test followed the profile in Figure 8 , and also went for its planned duration. This 205 second test acquired data at all hut one of the remaining steady state operating points of interest. ТТВ-(033 was initially meant to finish the series, hut it was stopped. prematurely due to a fire external to the engine not related to the pump. Post test inspections revealed a broken line had leaked hot gas. Repairs were performed, and TTB-034 ran the full 205 second duration as shown in Figure 9. This test successfully attained the $80 \%$ power level 827.4 KPa (120 psi) NPSP engine inlet condition, and warmer lox was used for the start transient without a change in performance. The linal test in the series was performed in June, 1992. Unfortunately, the proximity prohe oulput became highly erratic hefore the prohes hecime thermally stable prohe evaluation was not altained. This new design had performed well for a lotal of seven starts and 724.5 seconds. 


\section{Bearing Performance}

Bearing performance data analysis of the hydrostatic bearing on the TTB consisted of a determination of the performance of the hearing which included a repeatability evaluation, centered coefficient calculation, and an estimate of the dynamic load on the bearing. The repeatability evaluation showed no appreciable difference in the pressures and temperatures across the bearing, or the speed for $80 \%, 100 \%, 104 \%$, and $109 \%$ power levels. This lack of discrepancy in the operational characteristics led to the small band hetween the maximum and minimum rotordynamic coefficients across the bearing. Based on orbit plots, the dynamic load on the hearing was estimated to he hetween 490 to $2050 \mathrm{~N}$ (110 to $460 \mathrm{lbf}$ ) for the tests at power levels hetween $80 \%$ and 109\%. Data show that the bearing operated without any anomaly and could withstand the load experienced at the bearing location. The hydrostatic bearing could be run indefinitely without any problems provided that the operational characteristics remain within the trends of the data that has been collected to date.

Data was collected to determine the repeatahility in the operational characteristics of the hydrostatic hearing from test to test. If the hearing pressures and temperatures remain unchanged from test to test at different operating speeds, the hearing performance is judged to he essentially unchanged. Typical data from the upstream and downstream pressures and temperatures are summarized in Table I. The data reviewed indicate only the downstream pressure indicate appreciable variance from test to test. Downstream pressures were approximately $345 \mathrm{KPa}$ (50 psi) lower during low NPSH testing. However, because this difference is only a fraction of the total pressure drop, the performance of the bearing was essentially unchanged. Resulting pressures were below the vapor pressure of liquid oxygen but in order to vaporize the fluid must be at that state longer than the fluid is in the bearing. The velocity of the fluid at that point is approximately $400 \mathrm{~m} / \mathrm{s}(1300 \mathrm{ft} / \mathrm{s})$ for about $.025 \mathrm{~m}(0.1 \mathrm{in}$.) which is approximately 6 microseconds. Under these conditions, the fluid could he approximately $690 \mathrm{KPa}$ (100 psi) below the vapor pressure without cavitation.

Since the hearing did not experience substantial deviation in its operational characteristics, the hand hetween the maximum and minimum empirical rotordynamic coefficients of the hearing was small. Figures 12 contains the values for direct stiffness, cross-coupled stiffness, and the direct damping of the hearing during the testing. These coefficients, owing to the fact that the operating conditions were in the range of the design, compared well with the coefficients predicted during the design phase. Load capacity versus eccentricity of the hearing is depicted in Figure 1.3 al cach of the power levels. The coefficients showed only small differences in the maximum and minimum values verily the rohustness of the hydrodynamic and bearing design. Although error in the actual values of the coefficients could he as high as $50 \%$, the coefficients generally were predicted in such a manner to provide a conservative design.

\section{Dynamic Data}

The most significant dynamic data ohtained from the hydrostatic hearing pump was provided hy the proximity probes monitoring the rotor position at the hydrostatic bearing. No data ohserving actual rotor motion in the SSME HPOTP has previously heen available. The major source of uncerlainty relative to the proximity prohe data was the prohes calibration sensitivity to temperature changes. Due to the large thermal changes present when going from an ambient environment (1) a liquid oxygen environment ahsolute values of rotor position were difficult $t o$ determine. The most ohvious indication of the probes temperature dependence is in the initial 
"overshoot" seen in the proximity probe data,shown in Figure 14, after the pump reaches mainstage speed at approximately $4.2 \mathrm{sec}$. While some of the overshoot is due to pump thermal stabilization effects on the rotordynamic boundary conditions, a significant portion is due to the large temperature change experienced by the probe, approximately $40{ }^{\circ} \mathrm{R}$, during the start Iransient.

The proximity probe data obtained from this pump provided several interesting new insights intu the operation of the SSME HPOTP, in addition to providing data that was directly comparable (1) the rotordynamic analytical predictions. The most readily identifiably phenomenon observed in the proximity probe data was a relatively low frequency large precession of the rotor during the slart and cutoff transients. The precession is depicted in orbit plot of test TTB-(1)29 in Figure 15 and clearly visible in the frequency domain data of Figure 16. Originally, this motion was thought to he synchronous shaft motion and that either the hydrostatic hearing stiffness was much less than predicted or the loads were much greater. However, further analysis showed that this motion actually occurs at $10 \%$ of synchronous speed during the start transient and did not track speed well during the shutdown transient. The precession started shortly after the initial pump rotations and dropped out at approximately 20,000 RPM. The amplitude remained relatively constant at a level between 0.12 and $0.14 \mathrm{~mm}(.005$ and .006 in.) An investigation into possible excitation sources for this phenomena led to rotating stall in either the prehurner or main pump.

The identification of rotor motion associated with the rolating stall was considered a significam revelation. This phenomena had been measured in the laboratory in water for both the main pump and preburner pump. However, the magnitude and duration of the resulting forces were never fully understood or appreciated. The pump speed for the measured stall limit for hoth the prehurner and main pumps correspond to the speed at which the large motion ceased during start-up.

The discovery of this phenomenon in the rotor motion has heen attributed to the fact that the proximity prohe data was the first good data detining rotor orbit motion. As mentioned previously, the significance of the presence of the phenomenon in the hydrostatic bearing configuration led to a greater appreciation of its existence. Previous isolator strain gage data was only viewed from a bearing load standpoint with frequency content during the transient heing difficult to observe. The characteristics associated with rotor motion during stall were quite consistent from test fo lest. A tabulation of several characteristics associated with the precession for all the tests are listed in Tahle II.

A comparison of data, ohtained from Phase Il pump isolator strain gage data and the hydrustatic hearing proximity probes, exhibiting this phenomenon is shown in Figures 17 and 18 . Figure 17 is a comparison of the time history data during the start transient which clearly shows the same characteristics for both sets of data. Figure 18 contains an estimate of the dynamic loads calculated from hoth sets of data. The isolator strain gage loads were calculated with standard load reduction technique developed for these gages, while the hydrostatic hearing loads were estimated from the displacement and predicted hearing stiftness. It is evident that the loads are comparable and the deflections present are not unique to the hydrostatic bearing configuration.

Another interesting phenomenon discovered in the proximity probe data was that the rotor appeared to "center" itself in the hearing when the propellants filled the pump while the engine was being prepared for test. This occurred due to propellent pressure forces lifing the rolating asscmbly, which is almost vertical while attached to the engine, and bottoming the rotor on an axial stop which is perpendicular to the pump centerline resulting in the "straightening" the rotor assembly in the pump. The most attractive feature of this phenomenon was that although the shatt may not have heen exactly "centered", it did not contact the journal when pump rotation hegan. 
With no contact present there was no indication of liftoff during the start transient. This is significant since it indicates the rotor runs on a fluid film during the start transient and removes the opportunity for wear during engine start. Additionally, there appeared to be little indication of contact during the shutdown transient. No obvious indication of contact appears in the proximity probe data until at least $10 \mathrm{sec}$. after engine shutdown at which time the pump speed had dropped to very low levels. These rub characteristics appeared to be relatively benign in all tests. The time history data from a typical rub indication where the rotor deflections reach a limit or tlat spot is shown in Figure 19. Indications of rub characteristics during the shutdown transients are tabulated in Table III.

While not as spectacular, the proximity prohes also provided excellent data of rotor orhits and synchronous amplitudes during mainstage operation. Although, as previously mentioned, cemperature dependant prohe calibrations made it difficull to determine with great accuracy the ahsolute position of the rotor, the dynamic amplitudes, which are a much smaller portion of full scale, were more easily assessed for rotor orbit size. The significant conclusion with respect to this data is that the rotor orbits are very well hehaved and comparable in magnitude for all mainstage power levels.

Synchronous RMS amplitude time histories from the proximity probe data over a test with significant power level and inlet conditions variations contain little variation in rotor orbit amplitude. An example of the RMS amplitude throughout a test which included operation at $80 \%$ RPL is well as $109 \%$ RPL with minimum inlet pressure, worst case conditions, is provided in Figure 20. The amplitudes presented in this example include the maximum and minimum values ohierved during all tests. Based on this data, the synchronous amplitudes of the rotating assembly were helween 2.5 and $7 \mathrm{mV}$ RMS, which corresponds to a peak (1) peak amplitude of hetween $0.0(1) 5$ and $0.015 \mathrm{~mm}(0.0(0) 2$ and 0.000$) 6 \mathrm{in}$.). Due to these small amplitudes, the potential error in the absolute value of the orhit size, due to calibration uncertainties, is helieved to he less than $0(12 \mathrm{~mm}(0.0001 \mathrm{in}$.$) . Additionally, no significant harmonics of synchronous, other than those$ ciased by blade wake forces as would he expected, were present in the data.

Although the absolute rotor position was difficult to discern due to probe calibration uncertaintics, a fairly simple method was used in an attempt to anchor the rotor position with respect 10 the hearing bore. The alternative method used rotor orbits believed to be indicative of ruh during shutdown as a means of locating the bearing bore and subsequently obtaining rotor positions relative to that point. It is believed that this method produced absolute rotor orbit positions representative of values for comparison to the analytical predictions. Using the data in this manner rotor orbit positions at various power level and vent conditions were predicted. A typical set of these results for test TTB-032 are shown in Figure 21.

The rotor positions and orbit amplitudes obtained from the proximity probe data compared favorably with orbit predictions from the rotordynamic analysis. To maintain the rub margins desired. the rotordynamic analyses predicted the fixed displacement at the hydrostatic hearing would he less than approximately $0.10 \mathrm{~mm}(0.0(14 \mathrm{in}$.) with peak to peak synchronous amplitudes in the range of approximately $.125 \mathrm{~mm}(0.001 \mathrm{in}$.). Based on the results similar to those presented in Figure 21, the fixed displacements were between .051 and $.10 \mathrm{~mm}(.002$ and .004 in.) with the synchronous amplitudes somewhat less than $0.025 \mathrm{~mm}(.001 \mathrm{in}$.$) .$

The data ohlained from the standard external alecelerometers and strain gages was evalualled on the same level as a lypical Pliase II HPOTP hotlire lest for comparalive purposes. The review consists of treguency domain data as well as time history dala. All the data reviewed compared 
favorably with a typical pump. The frequency domain data contained no significant anomalies or indications of detrimental conditions occurring during testing. Very slight indications of the low frequency precession phenomenon, which is atypical of external instrumentation, were present in the data. Harmonics of synchronous present in the data are comparable to those seen in the Phase II conliguration.

The time history data for all instrumentation reviewed was nominal. Synchronous amplitudes were helow 2 Grms on all accelerometers and below nominal Phase II pump values on a majority of the accelerometers. No significant amplitude changes were identified during power level excursions or inlet condition excursions. Additionally, composite RMS values and synchronous harmonic values were well within the Phase II database. A typical RMS amplitude time history of the synchronous amplitude from the accelerometer data is presented in Figure 22.

The turbine cartridge strain gages which,primarily intended for axial displacement measurements, were also reviewed for high frequency characteristics. Although low amplitude intermittent hearing cage harmonics were identified on these strain gages, this activity at a low amplitude is considered typical for this instrumentation which is so closely coupled with the bearing carrier, and is not considered to be detrimental. Additionally, the synchronous amplitudes were comparable (1) previously measured data from SSME pumps The significance of this data is the confirmation that the implementation of the hydrostatic bearing did not result in any detrimental conditions at the turbine end hearings. This is of interest because the turbine hearing package contained separate modifications which have heen demonstrated in other development pumps to resolve turhine hearing wear issues occasionally present in Phase II HPOTPS.

\section{Plume Snectroscony Information}

The Optical Plume Anomaly Detector (OPAD) showed no conclusive evidence of silver during any test in this series. However, the OPAD system had not been calihrated for silver hy plume sceding, and the NASA SP-273 chemical equilibrium code did not contain a complete sel of reaclants data for silver. Therefore, the system was limited to using primarily statistical metheds with comparison to data collected on TTB tests 20 through 28 , which had standard HP(OTP hearing configurations. Because of this difficulty and the micro-wiggle measurements minimal silver, if any, was helieved to have been ingested by the main injector.

\section{Conclusions}

The implementation of the hydrostatic bearing met or exceeded the rotordynamic requirements set forth. The data indicated no significant wear occurred due to rubbing during the transients and the rotor displacements were well behaved during all operating conditions. No rotordynamic issues resulted during the testing to $109 \%$ rated power levels and minimum NPSH, and the test program provided new insight into the operation of the SSME HPOTP.

\section{$\underline{\text { Reterences }}$}

'Lomakin, A., "Calculation of Critical Speed and Securing of Dynamic Stability of the Rolor' of Hydraulic High Pressure Machines with Reference to Forces Arising in the Seal Gaps," Energomashinostrocnic, Vol. 4, No. 4, pp. 1-5, April 1958. 
${ }^{2}$ Black, H.F., "Effects of Hydraulic Forces in Annular Pressure Seals on the Vihration of Centrifugal Pump Rotors," Journal of Mechanical Engineering Science, Vol. 11, No. 2, p p. 206-213,1969.

'Jensen, D.N., "Dynamics of Rotor Systems Embodying High Pressure Ring Seals," Plud.Dissertation, Heriot-Watt University, Edinhurgh,Scotland, July 1970.

${ }^{4}$ Black, H.F. and Jenssen, D.N., "Dynamic Hybrid Properties of Annular Pressure Seals," Proc.Journal of Mechanical Engineering, Vol. 184, pp.92-100, 1970.

'Black, H.F. and Jenssen, D.N., "Effects of High Pressure Ring Seals on Pump Rotor Vibrations."ASME paper No. 71-WA/FE-38, 1971.

"von Pragenau, G., "Damping Seals for Turbomachinery,* NASA TP-1987, March 1982.

${ }^{7}$ Childs, D.W. and Kim, C.-H., "Analysis and Testing for Rotordynamic Coefficients of Turbulent Annular Seals with Directionally Homogeneous Surface-Roughness Treatment for Rotor and Stator Elements," Trans. ASME Journal of Tribology, Vol. 107, July 1985, pp. 296-306.

${ }^{x}$ Childs, D.W. and Kim, C.-H., "Testing for Rotordynamic Coefficients and Leakage: Circumferentially-Grooved Turhulent Annular Seals," proceeding of the IFToMM Internalional Conference on Rotordynamics, Tokyo, Japan, Sept. 1986, pp. 60\%9-618.

"Childs, D., and Kim, Chang-Ho, "Test Results for Round-Hole Pattern Damper Seals: Optimum Configurations and Dimensions for Maximum Net Damping, ASME Transactions, Journal of Trihology, Vol. 108, October 1986, pp. 605-611.

"Childs, D.W. and Garcia, F., "Test Results for Sawtooth Pattern Damper Seals: Leakage and Rotordynamic Coefficients," ASME Journal of Tribology, Vol. 109, January 1987, pp. 124-128.

"Kim, C-H, and Childs, D., "Analysis for Rotordynamic Coefficients of Helically-Grooved Turbulent Annular Seals," ASME Transaction Journal of Tribology, Vol. 109, January 1987, pp. 136-143.

${ }^{12}$ Scharrer, J.K., Hibbs, R.I., Nolan, S.A., and Nolan, S.A., "Extending the Life of the SSMe HPOTP Through the Use of Annular Hydrostatic Bearings", AIAA paper no. 92-3401, July 1992.

${ }^{17}$ Genge, Gary G., "Developing Acceptance Limits for Measured Bearing Wear of the Space Shuttle Main Engine High Pressure Oxidizer Turhopump". AIAA 91-2412, 27th Annual Joint Propulsion Conference, June 24 to 26, 1991.

${ }^{H}$ Scharrer, J.K., Tellicr, J.G. and Hihhs, R.I., "Start Transient Testing of an Annular Hydrostatic Bearing in Liyuid Oxygen". AlAA 92-3404, 28th Annual Join Propulsion Conference, July 6 (6) $x, 1992$.

${ }^{15}$ Cooper, A.E., Powers, W.T., and Wallace,T.L. "OPAD Status Report: Investigation of SSME Component Erosion". SAE 921030, 1992 Socicly of Automotive Enginecrs Aerospace Allantic Conference in Dayton, Ohio, April 71010. 
Tahle I: TTB Engine 404 LOX Bearing Tests.

\begin{tabular}{|c|c|c|c|c|c|}
\hline $\begin{array}{c}\text { Power } \\
\text { Level }\end{array}$ & $\begin{array}{c}\text { Speed } \\
(\mathrm{rpm})\end{array}$ & $\begin{array}{c}\text { U/S Pr } \\
(\mathrm{p} \text { sia) }\end{array}$ & $\begin{array}{c}\text { D/S Pr } \\
(\mathrm{psia})\end{array}$ & $\begin{array}{c}\text { U/S Temp } \\
(\mathrm{R})\end{array}$ & $\begin{array}{c}\text { D/S Temp } \\
(\mathrm{R})\end{array}$ \\
\hline 80 & 23,400 & 4150 & 210 & 199 & 212 \\
\hline 100 & 27,700 & 5450 & 230 & 212 & 230 \\
\hline 104 & 28,500 & 5700 & 250 & 216 & 233 \\
\hline 109 & 29,700 & 6100 & 250 & 220 & 237 \\
\hline
\end{tabular}

Table II: Precession Characteristics

\begin{tabular}{||l|l|l|l|l||}
\hline & $\begin{array}{l}\text { Start } \\
\text { Dropout }\end{array}$ & $\begin{array}{l}\text { Cutoff } \\
\text { Resumption }\end{array}$ & \\
\hline & Time & Speed & Time & Speed \\
\hline Test & E/S+sec & RPM & C/O+sec & RPM \\
\hline $801-029$ & 3.05 & 20,400 & 0.5 & $16,800)$ \\
\hline $801-030$ & N/A & & & \\
\hline $801-031$ & 3.1 & 21,500 & 0.4 & 16,500 \\
\hline $801-032$ & 3.1 & 21,000 & 0.25 & 17,500 \\
\hline $801-033$ & 3.1 & 21,000 & 0.5 & 18,000 \\
\hline $801-034$ & 3.05 & 21,500 & 0.3 & 16,800 \\
\hline $801-(1) 35$ & 2.952 & $20,5(x)$ & 0.5 & $18,(x) 0$ \\
\hline
\end{tabular}

Table III: Ruh Indications

\begin{tabular}{|l|l|l||}
\hline & Time of Ruh & Speed $@$ Ruh \\
\hline Test & C/O+sec & RPM \\
\hline TTB-029 & 11.0 & 550 \\
\hline TTB-030 & None Obvious & \\
\hline TTB-031 & 10.7 & 750 \\
\hline TTB-032 & 15.2 & 700 \\
\hline TTB-033 & 15.0 & 650 \\
\hline TTB-034 & None Ohvious & \\
\hline TTB-035 & 14.0 & 700 \\
\hline
\end{tabular}




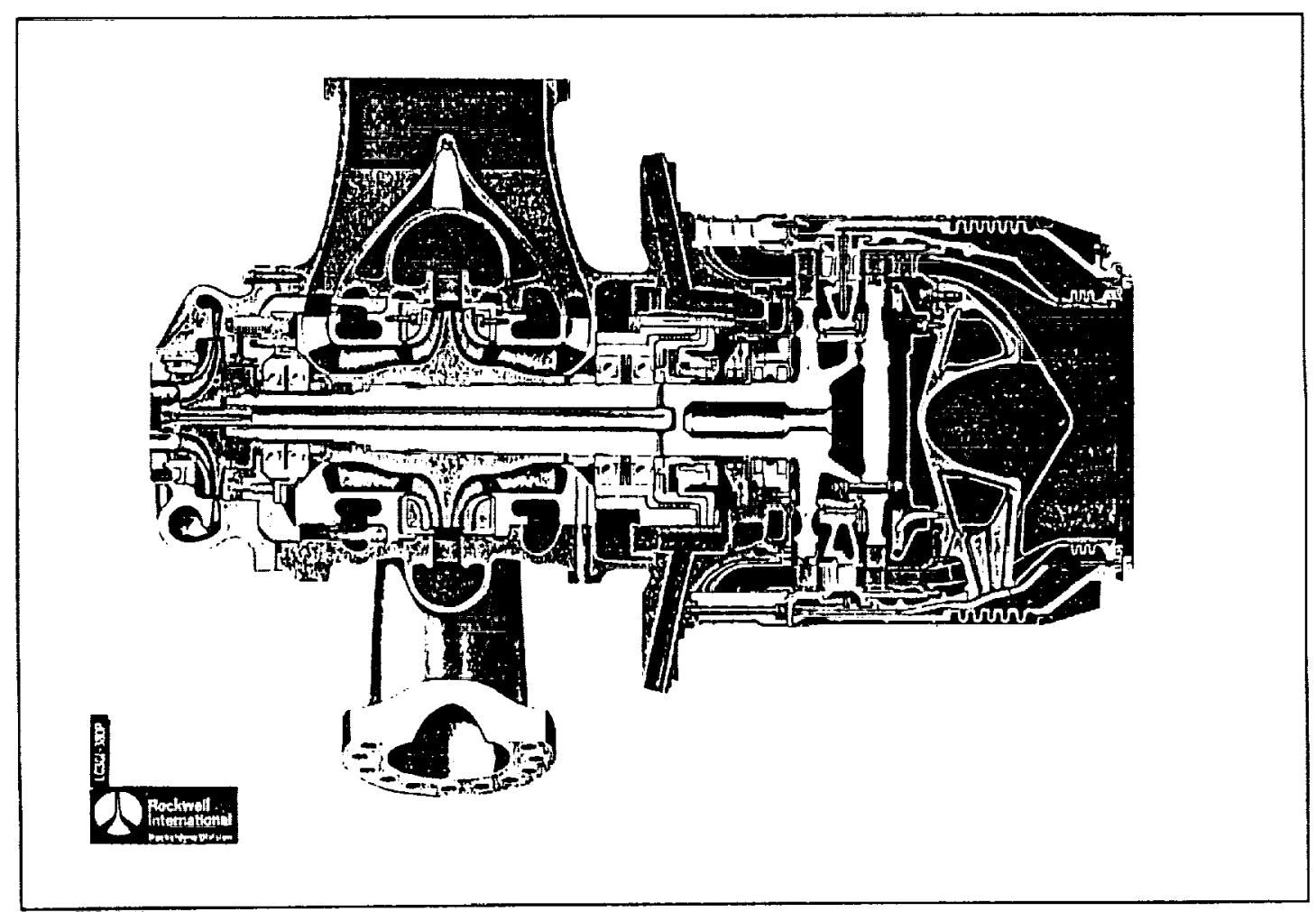

Figure 1. Phase II SSME HPOTP.

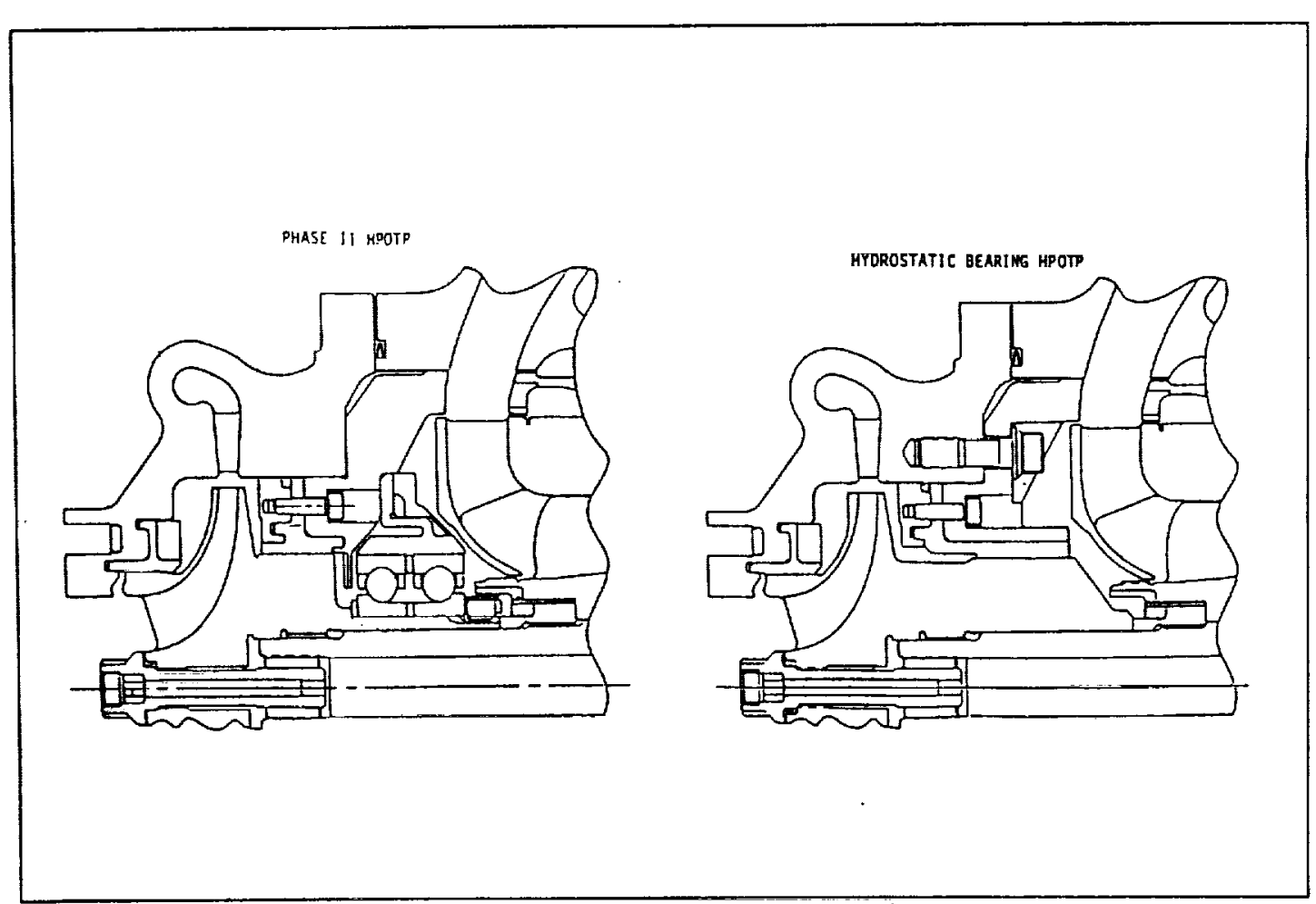

Figure 2. Hydrostatic Bearing Modification. 


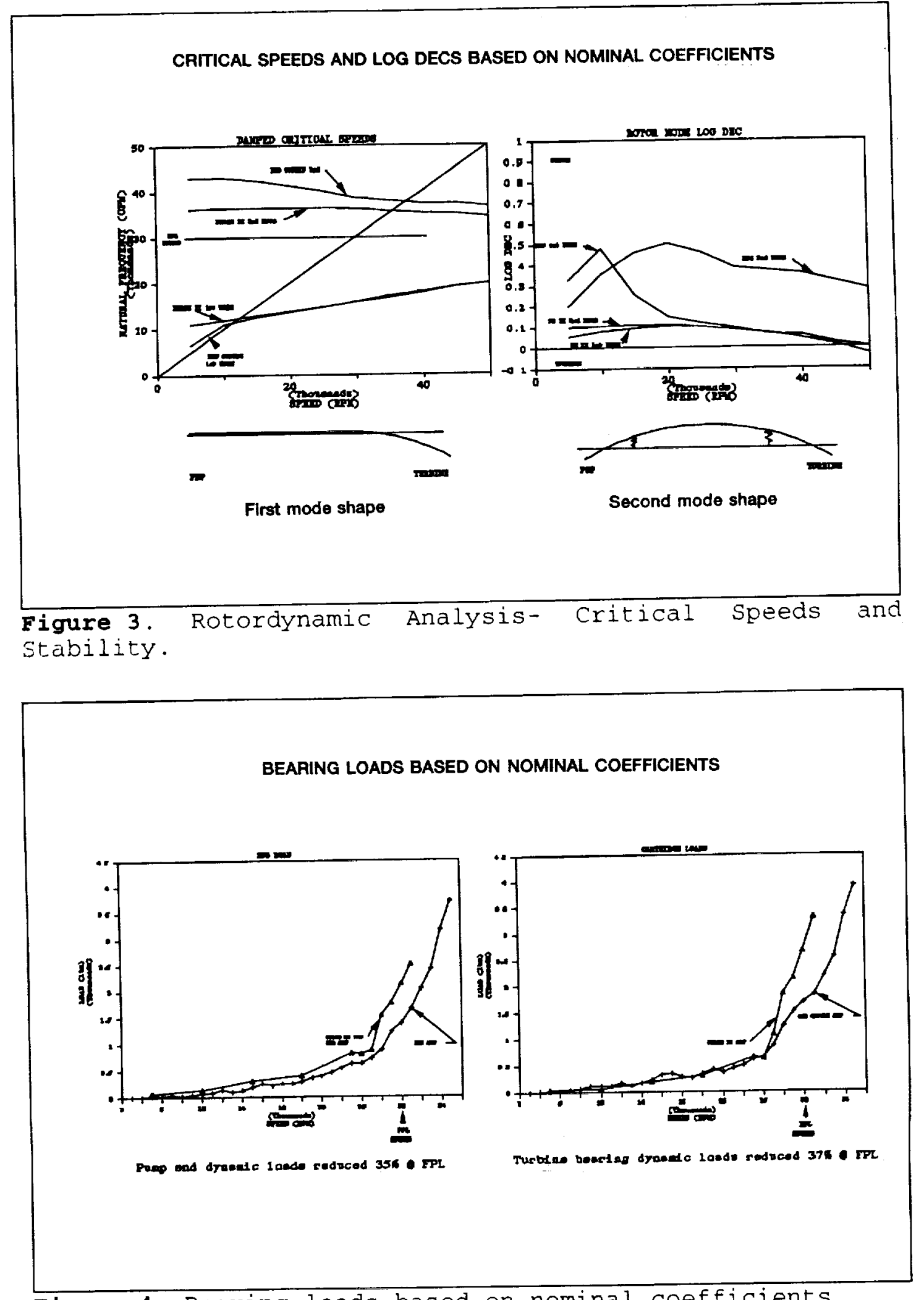

Figure 4. Bearing loads based on nominal coefficients. 


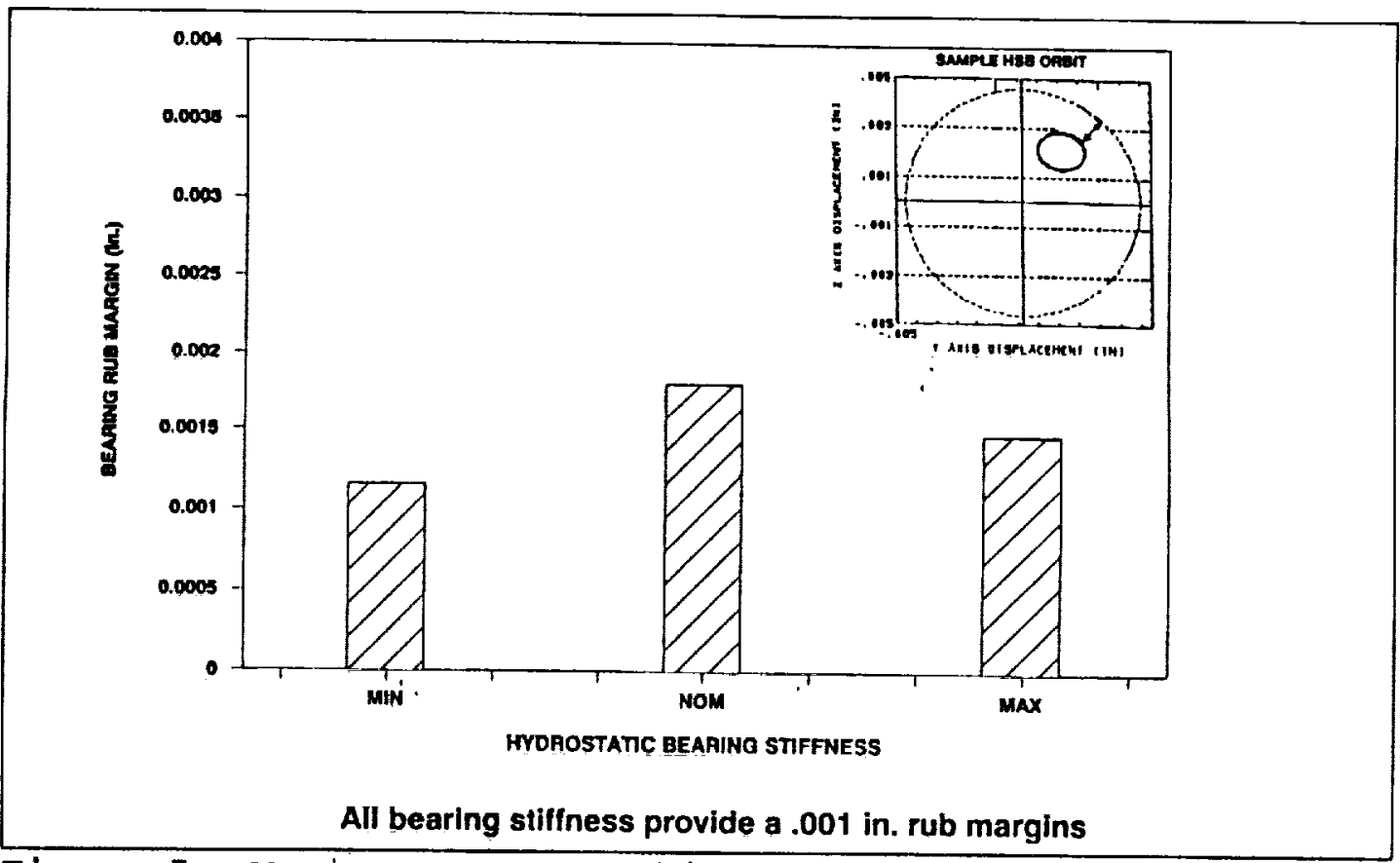

Figure 5. Maximum rotor orbit to minimum seal clearance margins.

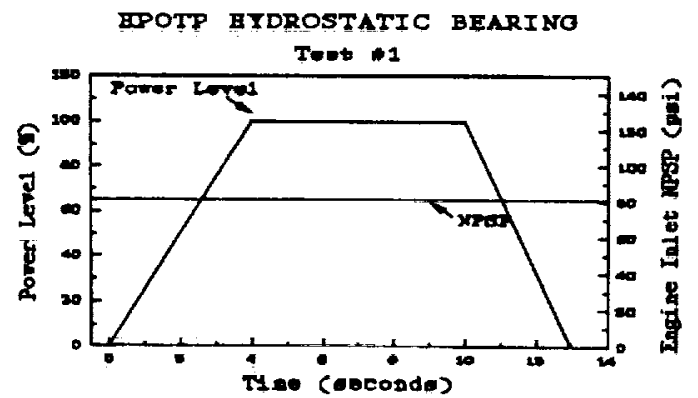

Figure 6. Hydrostatic hearing test \#1.

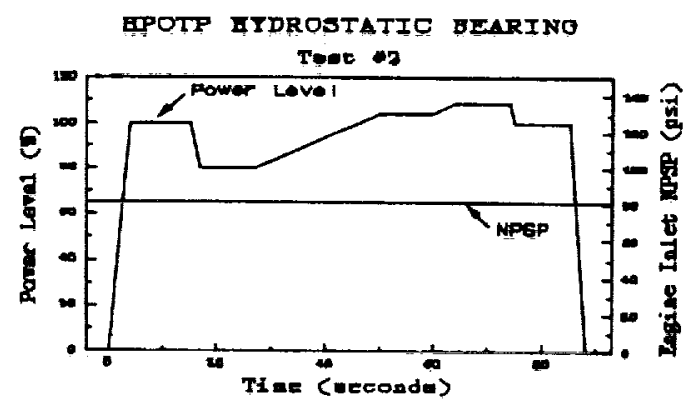

Figure 7. Hydrostalic hearing lest \#2.

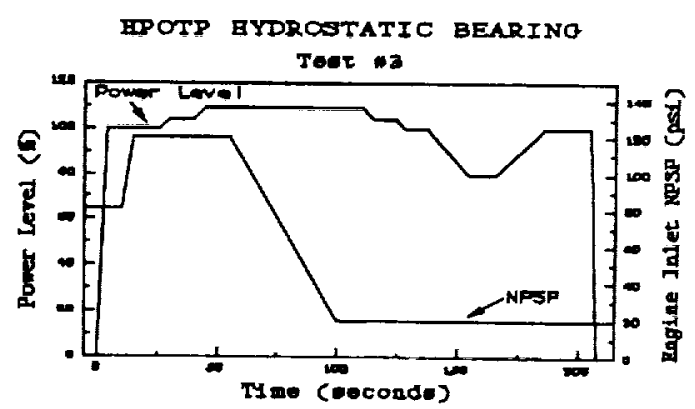

Figure 8. Hydrostatic hearing test \#3.

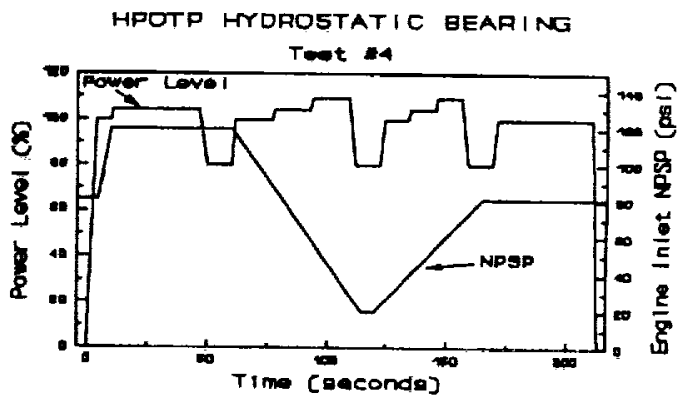

Figure 9. Hydrostatic hearing test \#4. 


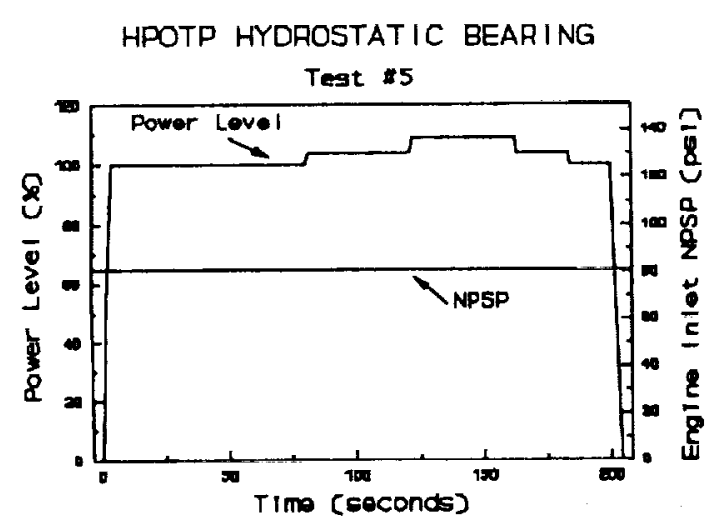

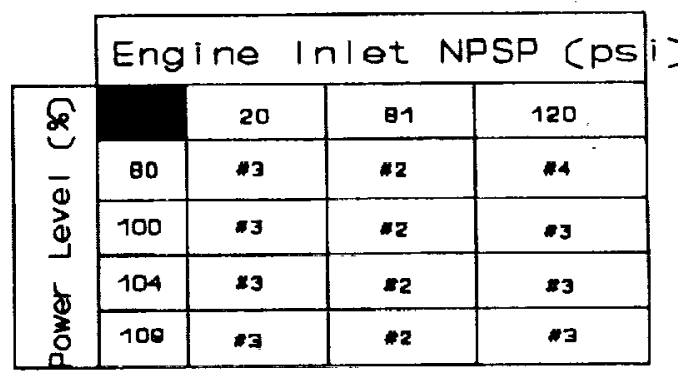

Figure 11. Test condition matrix.

Figure 10. Hydrostatic hearing test \#5.

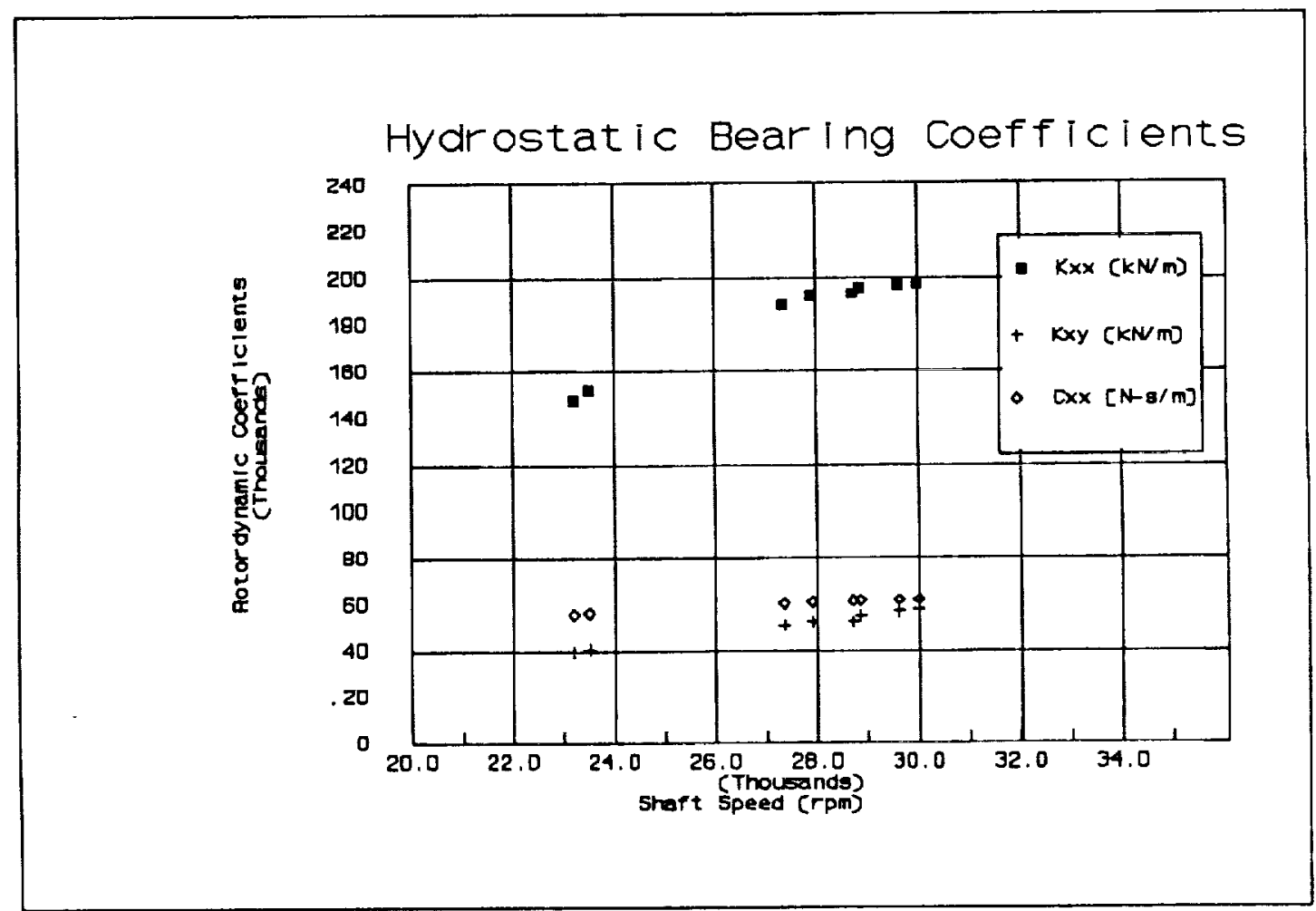

Figure 12. Hydrostatic hearing rotordynamic coefficients. 


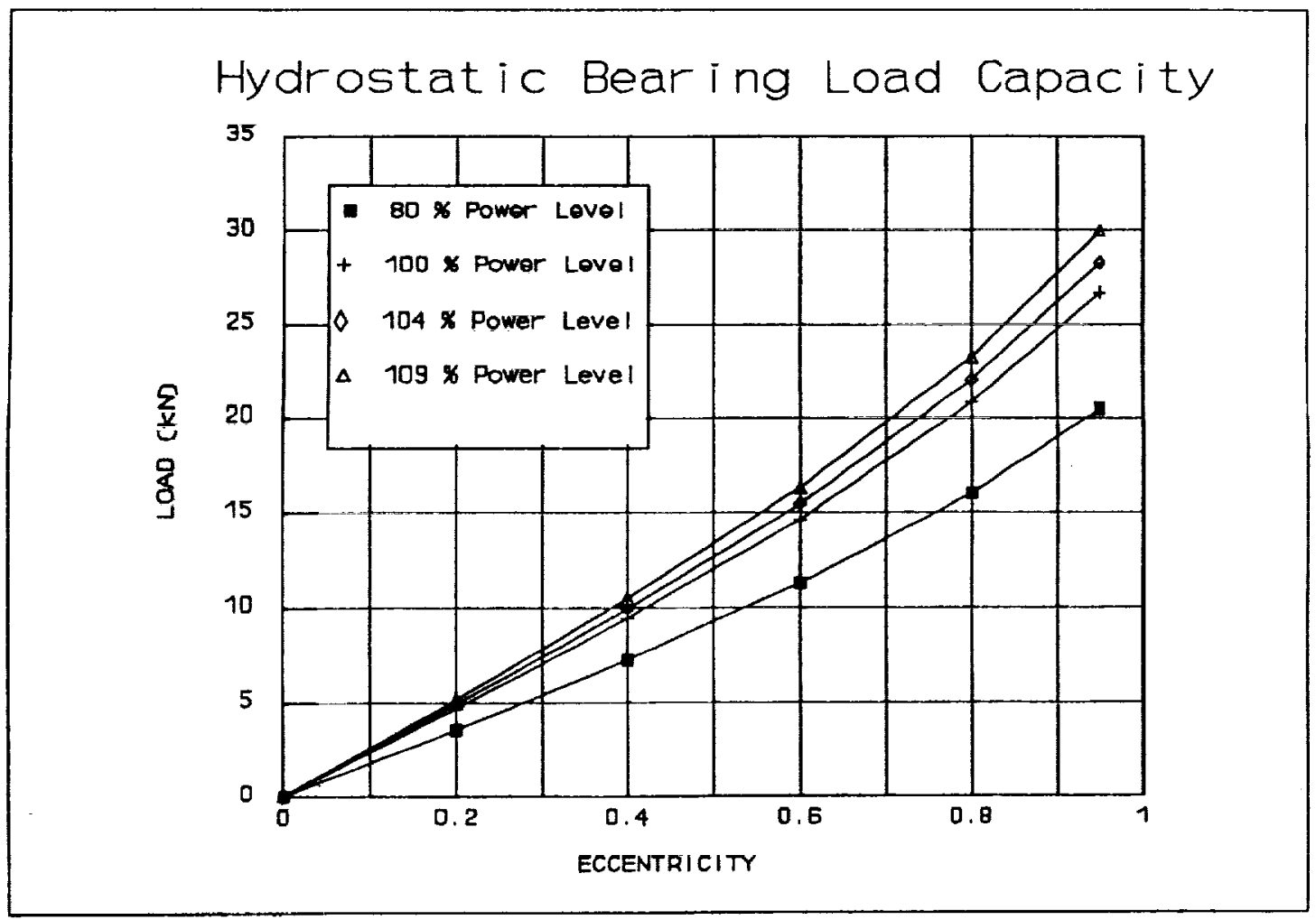

Figure 13. Hydrostatic hearing load capacity vs. eccentricity.

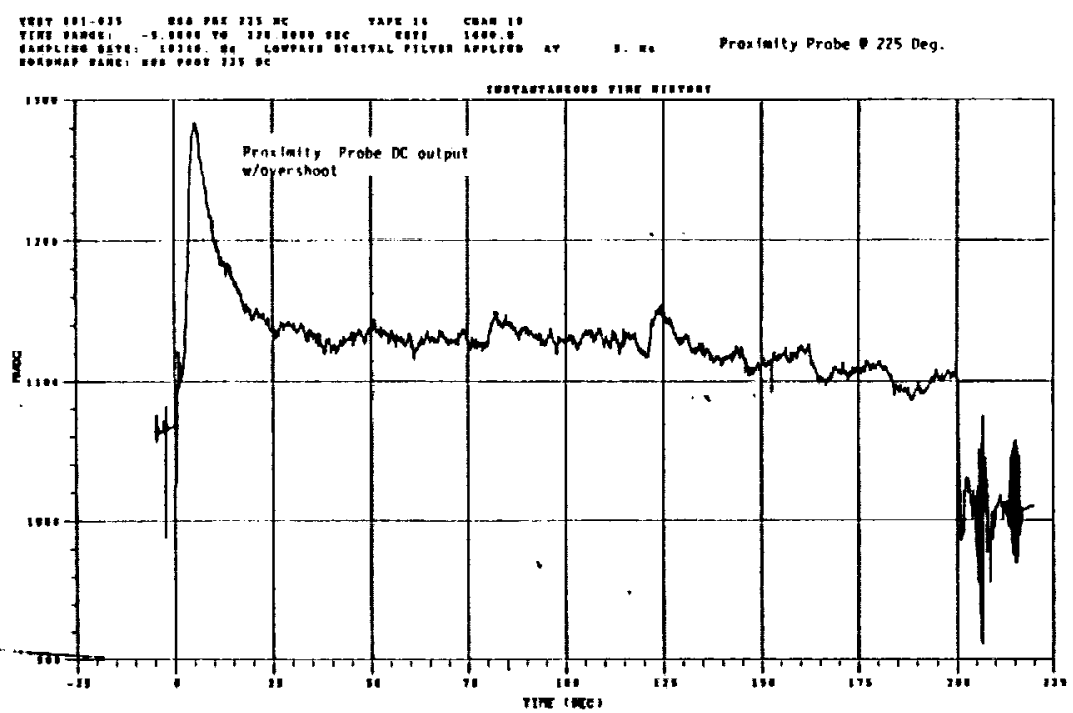

Figure 14. Proximity probe DC output. 


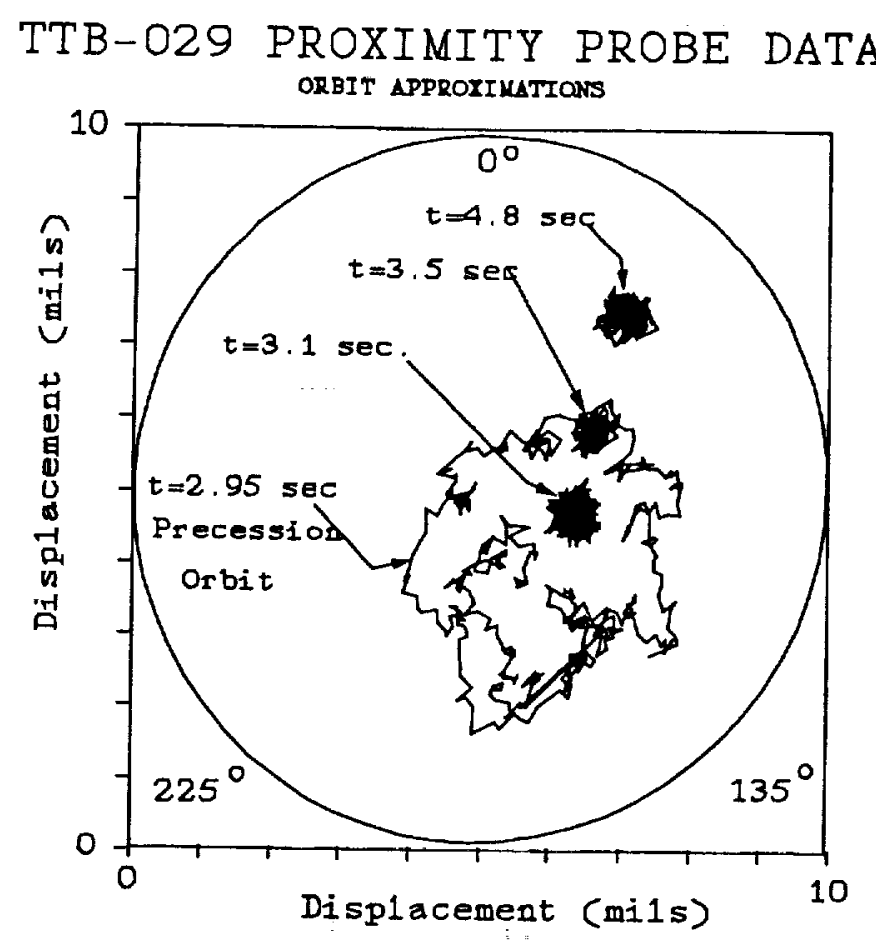

Figure 15. Test \#1 Hydrostatic bearing orbit data.

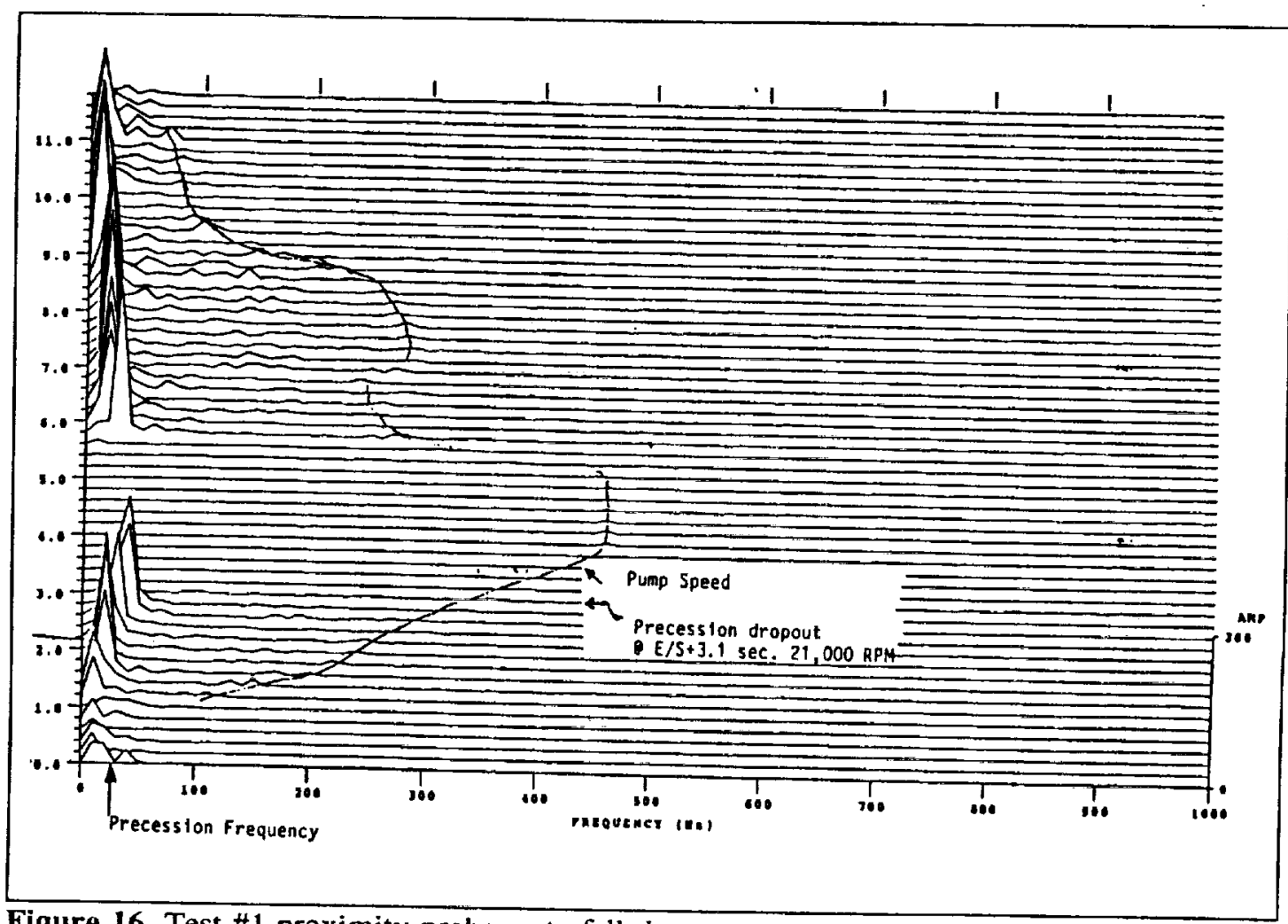

Figure 16. Test \#1 proximity probe waterfall data. 
"ne

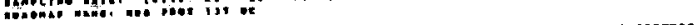

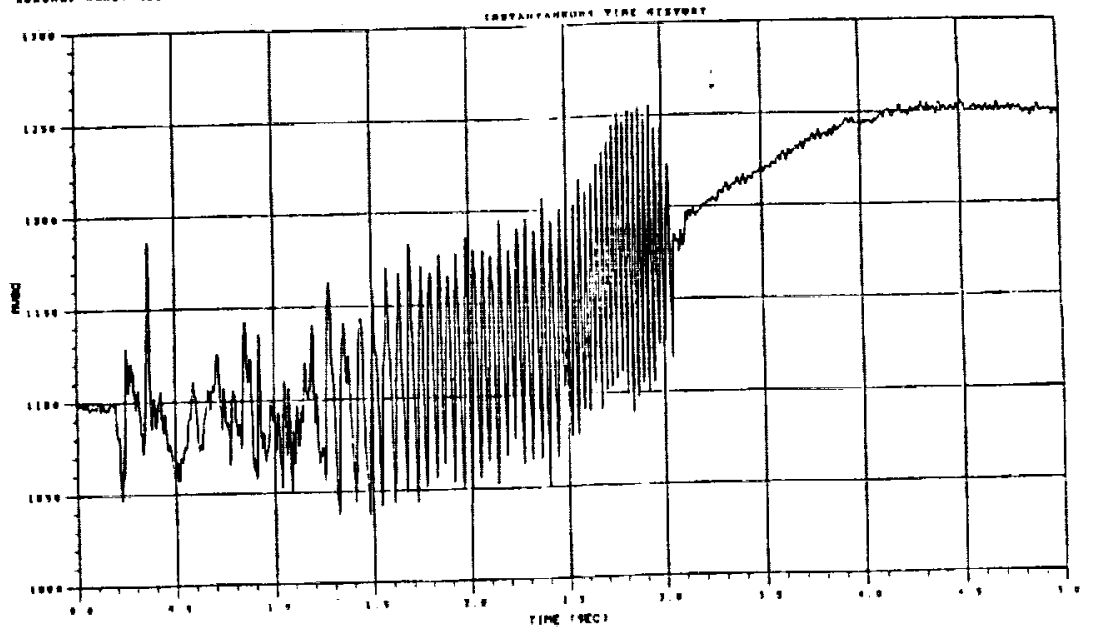

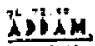

Strain Gage Output

Phase II Pump Isolator Strain Gag

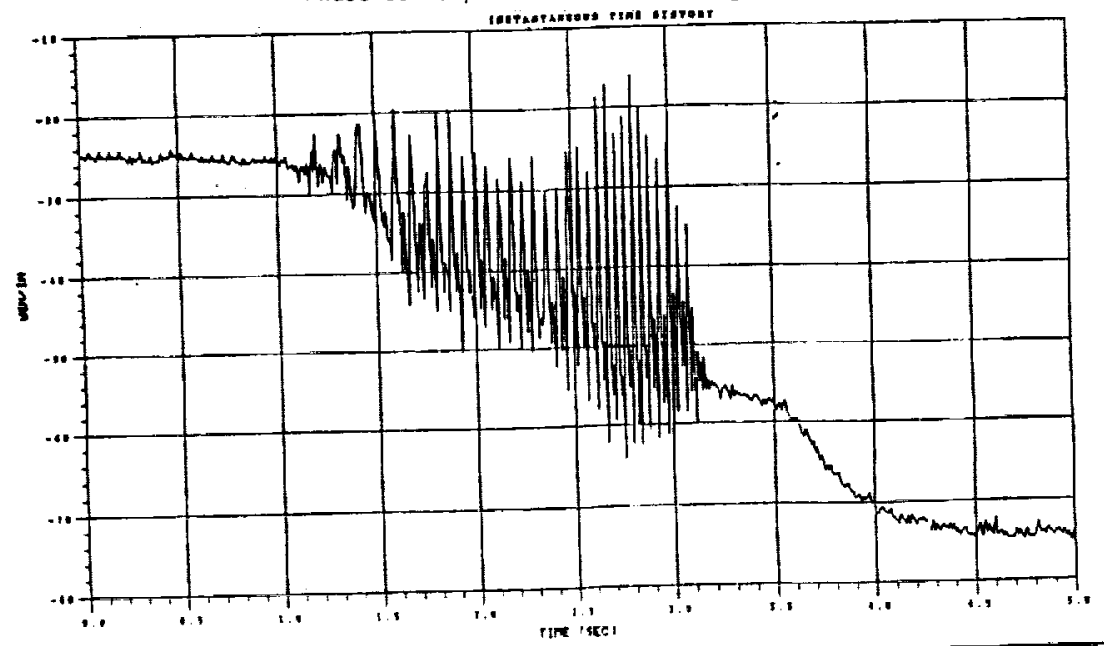

Figure 17. Ball hearing vs. hydrostatic hearing rotor motion as a function of time during the engine start transient. 

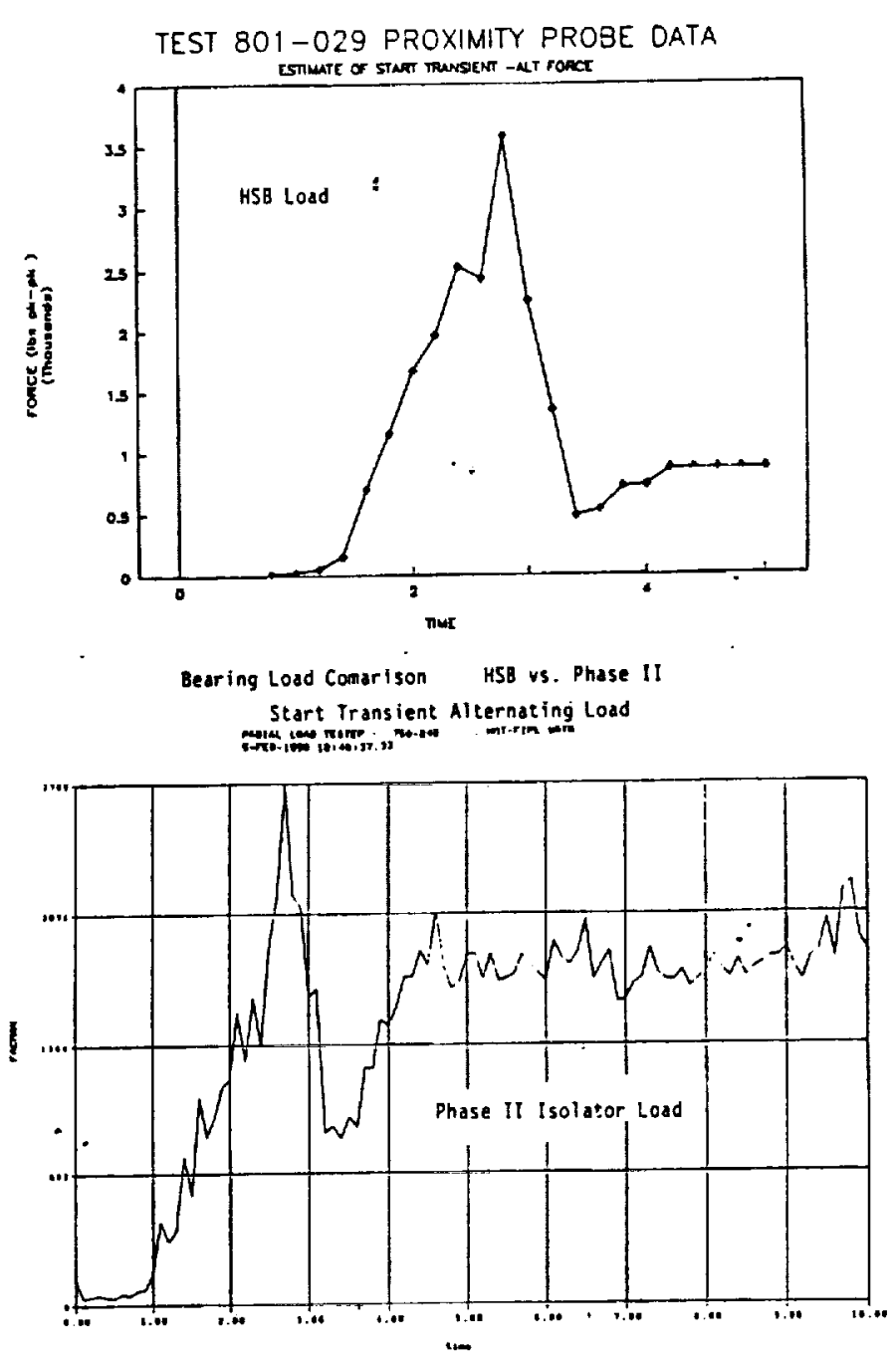

Figure 18. Ball hearing vs. hydrostatic hearing loads as a function of time during the start Iransient 


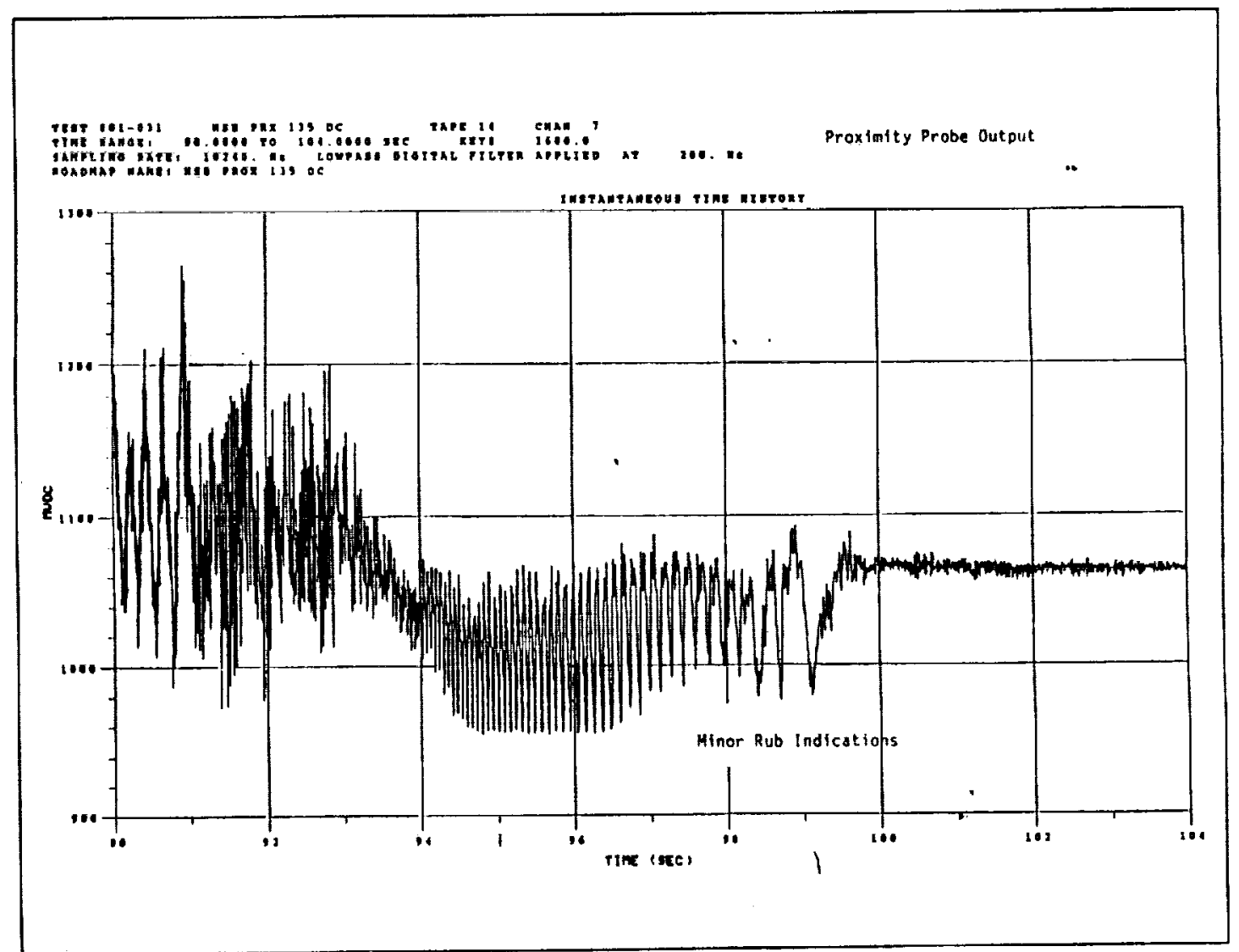

Figure 19. Proximity probe rub indications.

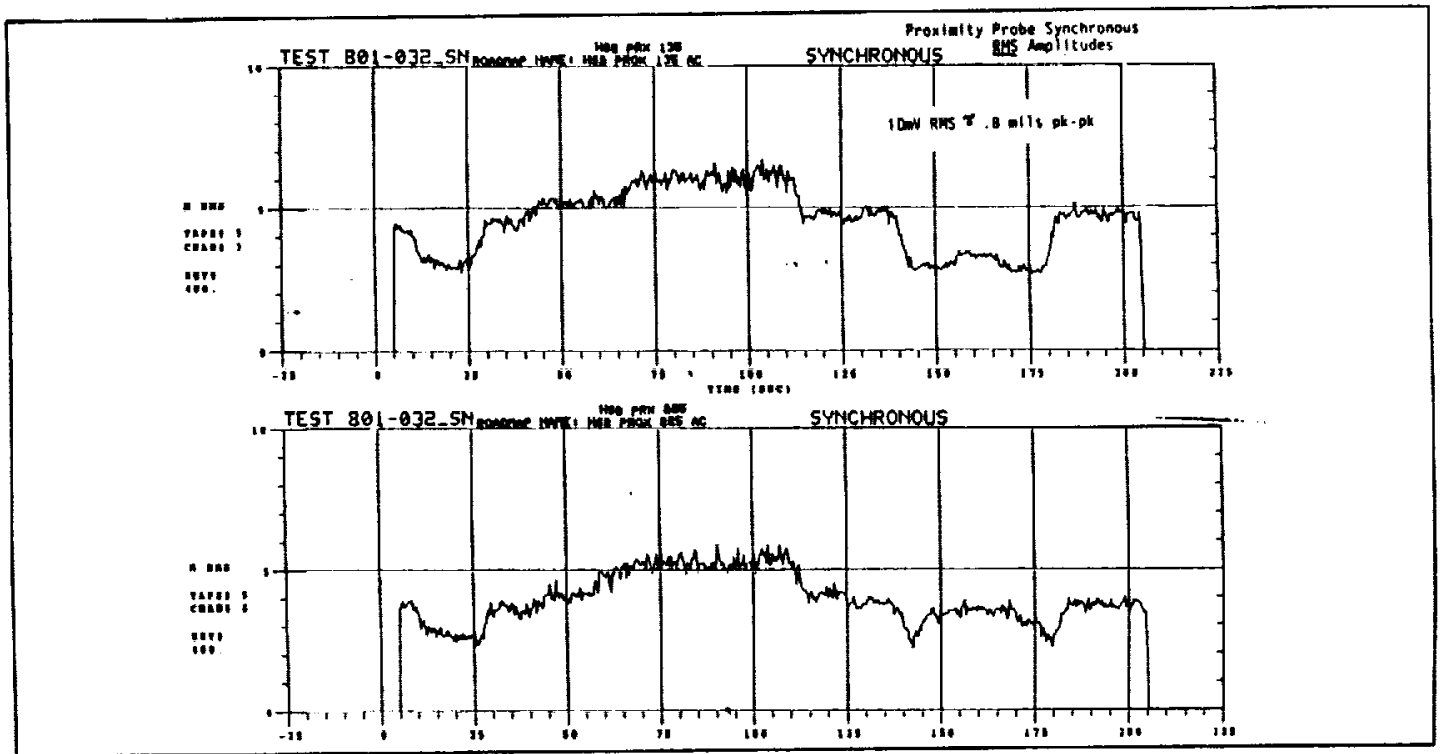

Figure 20. Proximity probe synchronous amplitudes. 


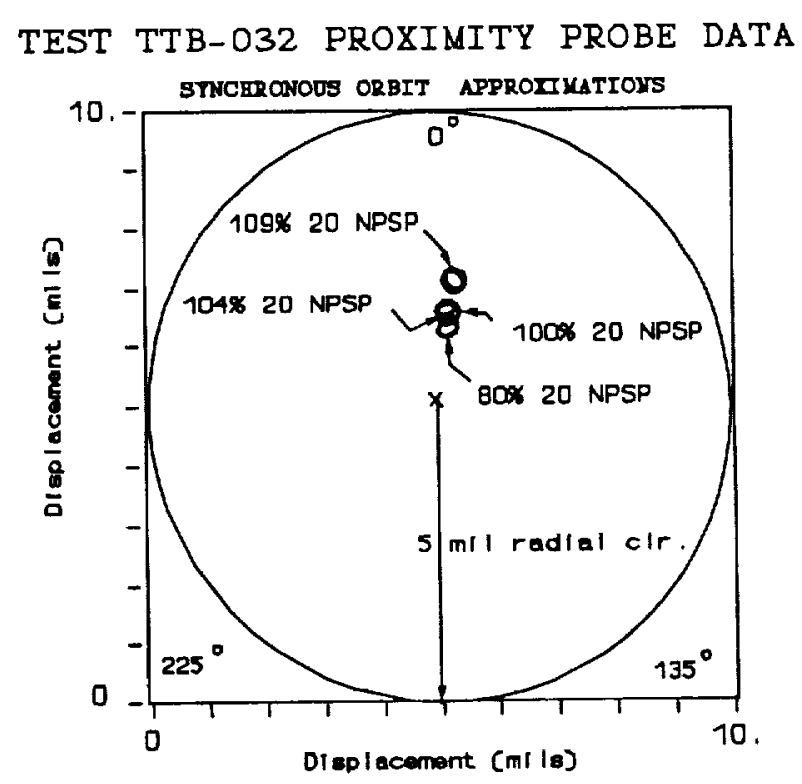

Figure 21. Rotor synchronous orbit amplitudes.

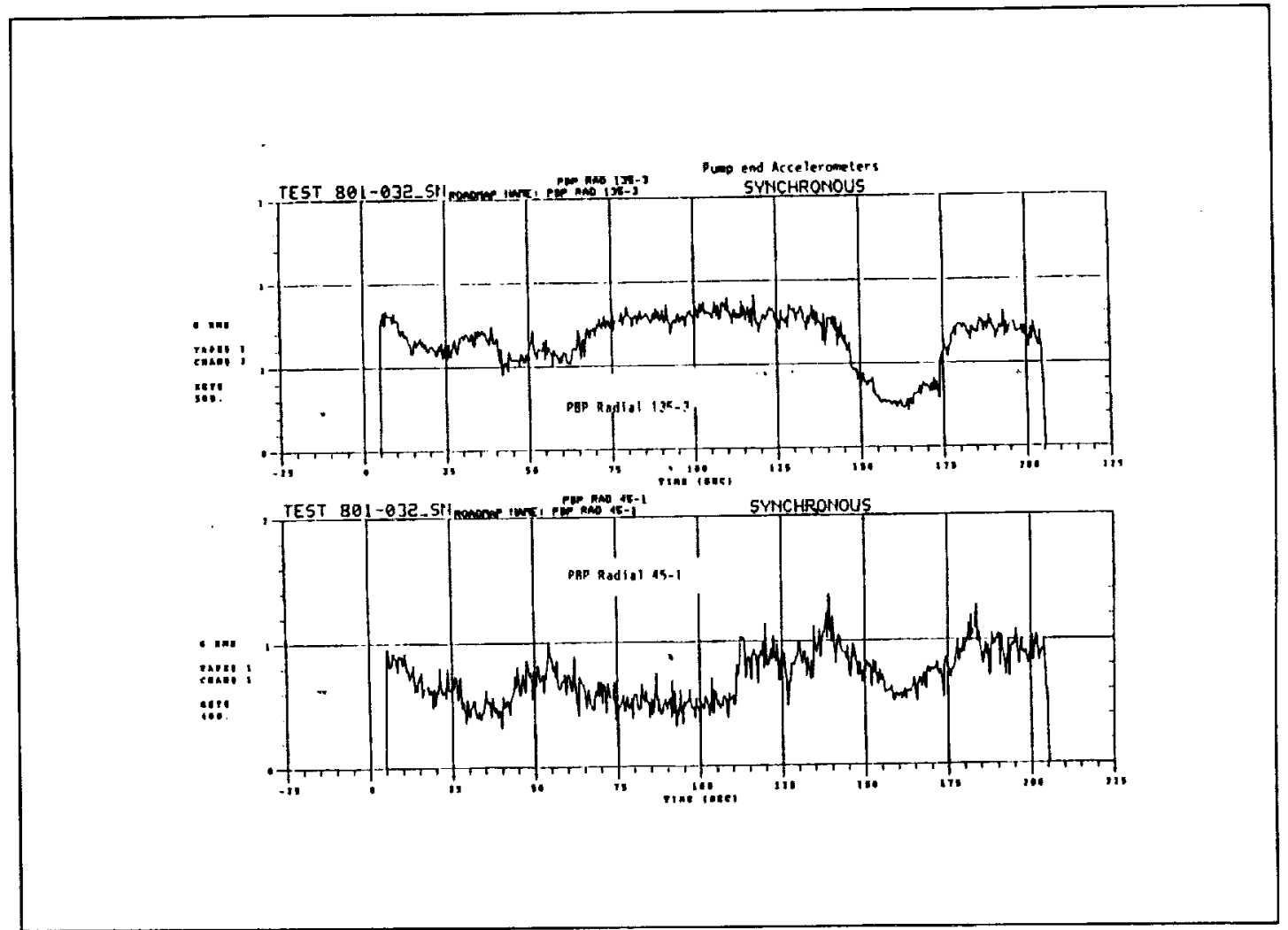

Figure 22. Casing accelerometer synchronous amplitudes. 
